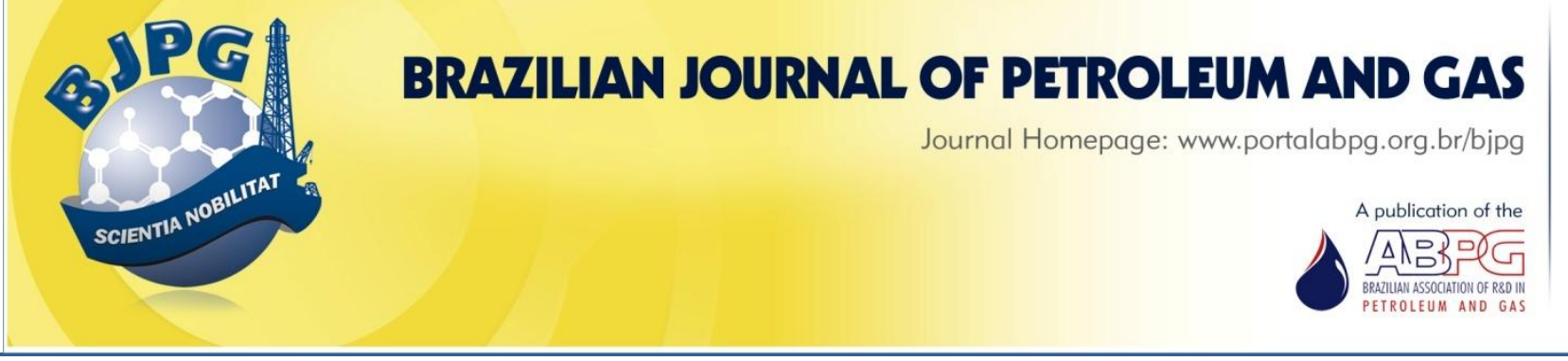

\title{
COMPUTATIONAL SIMULATION OF CYCLICAL STEAM INJECTION AND PNEUMATIC ARTIFICIAL LIFT SYSTEM WITH WATER SEAL FOR OIL RECOVERY
}

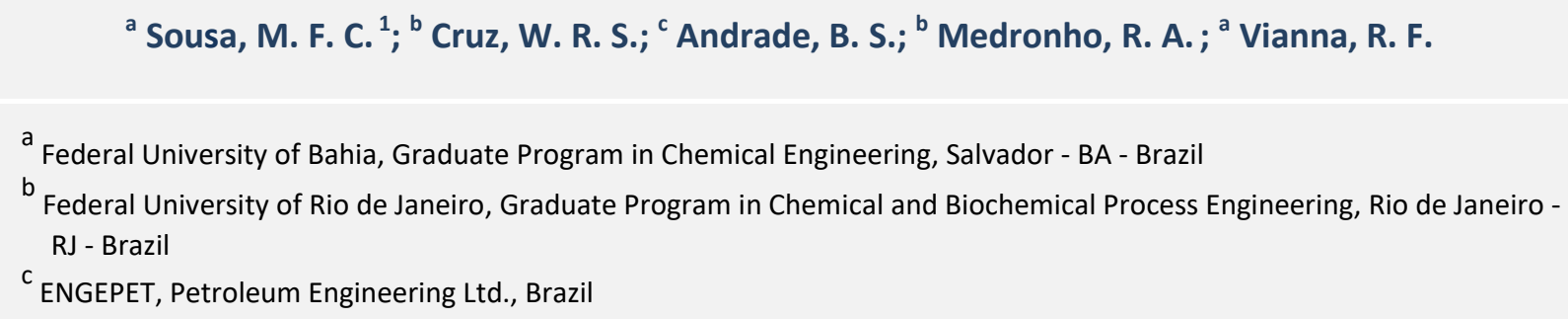

Received: 29.09.2018 / Revised: 25.11.2018 / Accepted: 16.01.2019 / Published on line: 03.04.2019

\begin{abstract}
Cyclic steam injection is an enhanced oil recovery (EOR) process which is characterized by oil viscosity reduction after the injection of steam into the well. However, like any thermal method, there is great concern regarding the excess of heat coming into the oil well casing, which is susceptible to thermal stress and may damage the reservoir. In order to solve this problem, the company ENGEPET developed the Cyclical Steam Injection and Pneumatic Artificial Lift with water seal (CSI/PAL/WS) system for temperature control in oil well casings. This work proposes a model for predicting the thermal exchange between the water and steam inside the CSI/PAL/WS system using Computational Fluid Dynamics (CFD). A simplified model was proposed and results show that it has great potential to contribute to the study of the CSI/PAL/WS system, as well as to predict operating conditions that may prevent the temperature of well casings to exceed safety limits.
\end{abstract}

\section{KEYWORDS}

EOR; cyclic steam injection; CSI/PAL system; CFD; modeling; thermal exchange

\footnotetext{
${ }^{1}$ To whom all correspondence should be addressed.

Address: Universidade Federal da Bahia, Rua Aristides Novis 2, Escola Politécnica, Federação, Salvador - BA, Brazil. ZIP Code: 40210-630 | Phone: +55(71)99998-7220| e-mail: marinafcsousa@gmail.com doi:10.5419/bjpg2019-0001
} 


\section{INTRODUCTION}

The demand for energy has been increasing over the years, and many industries have been searching for ways to increase their production. Recovery processes can be used to improve well production. Aiming at increasing oil recovery, one can make changes in reservoir characteristics. Primary recovery depends only on reservoir pressure, which means that the differential pressure between the reservoir and wellbore is responsible for driving the oil out of the production well. With the decline in the reservoir pressure, oil recovery also decreases, leading to the implementation of a secondary recovery method that involves water and immiscible gas injection. Furthermore, the oil industries adopt the enhanced oil recovery (EOR) process to increase oil production. This process is used typically in wells containing oil with high viscosity or presenting high interfacial tensions between the injected fluid and the oil. There are three main methods of EOR: miscible, chemical, and thermal (Costa et al., 2017; Rellegadla et al., 2017).

Miscible methods are best suited in case of low displacement efficiency, i.e., when the injected fluid cannot remove the oil out of the rock pores due to high interfacial tensions, since these methods are designed to reduce interfacial tensions substantially. Abedini and Torabi (2013), Safi et al. (2016), and Al Hinai et al. (2017) carried out studies about these methods. Rego et al. (2017), Pei et al. (2014), and Rellegadla et al. (2017) studied the injection of polymers, a chemical method, similar to miscible methods, that also aims at reducing interfacial tension between both oil and the polymer fluid. This method promotes fluid miscibility and increases displacement efficiency, assuming that there is a chemical interaction between the fluids.

In the natural mode of operation of wells with high-viscosity oil, the percentage recovery does not exceed $6-15 \%$. Thermal methods are recognized as one of the most effective ways to improve oil recovery (Belsky \& Korolyov, 2018). The main thermal methods are injection of heated fluids, usually hot water or steam, injected either continuously or in a cyclic way, as well as in situ combustion. Oliveira et al. (2015) discretized an actual reservoir in a simplified quadratic shape, with a five-spot injection scheme and simulating thermal (370K) and isothermal (323K) recovery methods with water. They verified that in case of employing thermal methodologies, the recovery factor is approximately $17 \%$ higher than for the isothermal cases. Wang et al. (2017) studied the application of AACSS (Air Assisted Cyclic Steam Stimulation) technique in an ultra-heavy oil reservoir. Their field results were analyzed along with a numerical reservoir simulation study. Pilot testing results indicated that the AACSS is capable of increasing oil production significantly, reducing the water cut, prolonging the effective production period, and improving the oil/steam ratio.

Nevertheless all stimulations performed in the reservoir have consequences. Accordingly to Alvarez e Han (2013), the introduction of heat into the rock formation produces stress and deformation of the oil casing, promoting thermal expansion of the rock grains and causing fractures and problems to its permeability. This becomes even worse considering that oil thermal recovery methods usually are applied to old wells where casings already have some damage and do not have the same thermal resistance as they did at the time of manufacture. Moreover, these wells generally are not prepared to receive steam injection or to endure high temperatures (Bo, 2014). In recent decades, computational fluid dynamics (CFD) technique has progressed substantially due to advances in numerical solution methods and computer technology, mainly related to computational speed, parallelization technology, and enhancement of software and multiphase algorithms (Zhang et al., 2013). Yin and Liu (2015) used CFD to study the influence of steam injection pressure, injection temperature, and hydraulic conductivity of the rock on the deformation of the cement and casing. They concluded that all three factors are capable of promoting casing damage. Bo (2014) developed a three-dimensional finite element model using CFD in order to investigate the influence of changing parameters such as material type, casing temperature control, and casing cementing under stress conditions. The author found that the reduction of casing temperature and/or thermal compression stress is necessary to prevent damage to the casing. 


\section{CSI/PAL AND CSI/PAL/WS SYSTEMS}

Cyclic steam injection uses a single well as producer and injector. It is composed by three stages: steam injection into the well, soaking, and production. This process requires workover operation for the injection system assembly and, later, for the production system, which implies loss of production during intervention time in addition to the costs and risks associated with these interventions. Considering this problem, ENGEPET (Empresa de Engenharia de Petróleo Ltda.) developed a Cyclical Steam Injection and Pneumatic Artificial Lift (CSI/PAL), a system that allows steam injection and oil lifting processes to be performed in a single structure through the addition of concentric columns to the lifting system BPZ (Type Z Pneumatic Pump) (Franco \& Miyaji, 2003; Gomez et al., 2012; Sousa et al., 2015). The CSI/PAL was tested at an oil field in Castanhal (Brazil). The results were compared with the mechanical pumping (MP) connected to the CPT (Composite Pumping Tree) method. The production using the CSI/PAL was $27 \%$ to $97 \%$ higher than those of MP with CPT, proving the efficiency of the method.
In order to reduce thermal stress of the well casing, the CSI/PAL system was modified, replacing the joint and thermal packer by a treated water flow used as a seal to control casing temperature. It can be used in projects of oil recovery employing cyclic steam injection process equipped with the CSI/PAL system. The CSI/PAL system with water seal (CSI/PAL/WS) is shown in Figure 1.

This work is inserted in the area of development of new technologies, such as the CSI/PAL/WS system, to improve the production of mature fields and heavy oils reservoirs. The challenge of this system is to overcome the thermal stress caused by cyclic steam injection. The advantage of CFD tool is that it provides a cost-effective way of obtaining a detailed understanding of a complex process, and, in some instances, it is the only available research tool to give an insight into the process behavior and trajectories that are difficult to evaluate using experimental techniques, as the CSI/PAL/WS system. Therefore, a new simulation CFD model is proposed allowing the study of the thermal exchange in the CSI/PAL/WS system.

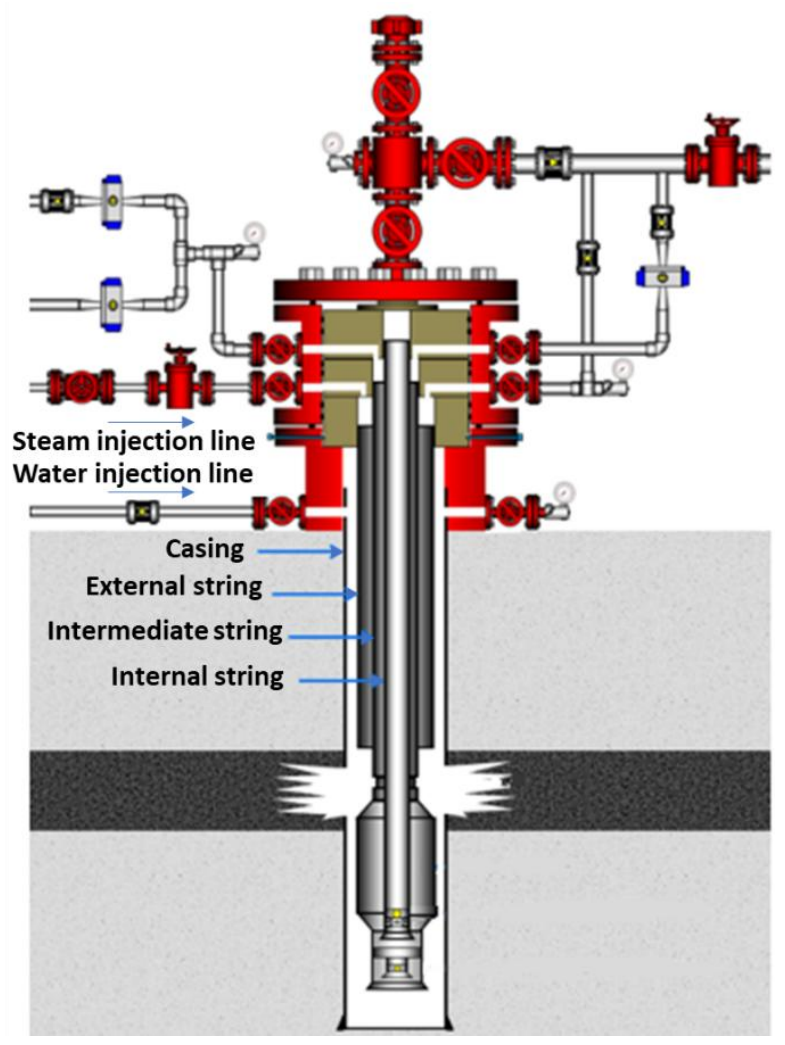

Figure 1. Cyclical Steam Injection and Pneumatic Artificial Lift System with Water Seal (CSI/PAL/WS). 


\section{METHODOLOGY}

Numerical simulations using the commercial CFD package Ansys 18.0 were performed. The computer employed had an 8-core $2.80 \mathrm{GHz}$ Intel (Core i7) processor and 8 GB RAM. Geometries and meshes were built using Design Modeler and Meshing, respectively. The setup was carried out in the CFX Pre, and the simulations in the CFX Solver. The results were analyzed using the CFD Post. All these software are part of ANSYS 18.0 package.

\subsection{Mathematical modelling}

The set of equations solved by ANSYS CFX comprise the Navier-Stokes equations in their conservation form: continuity (Eq. 1), momentum (Eq. 2), and energy (Eq. 3).

$\frac{\partial \rho}{\partial t}+\nabla \cdot(\rho u)=0$

$\frac{\partial(\rho u)}{\partial t}+\nabla \cdot(\rho u \otimes u)=-\nabla p+\nabla \cdot \tau+S_{M}$

$\frac{\partial(\rho h)}{\partial t}+\nabla \cdot(\rho u h)=\nabla \cdot(\lambda \nabla T)+\tau: \nabla u+S_{E}$

Where $\rho$ is the density, $t$ is the time, $u$ is the velocity vector, $p$ is the pressure, $\tau$ is the vectorial shear stress, $S_{M}$ is the momentum source, $h$ is the internal energy, $T$ is the temperature, $S_{E}$ is the energy source, and the term $\tau: \nabla U$ is the viscous dissipation which is always positive.

\subsection{Geometry and mesh}

In order to reduce computational effort, the original geometry of the CSI/PAL/WS system was simplified by considering only representative columns. The two-domain model (Figure 2) considered two concentric external annular columns for the flowing of water and steam, respectively, separated by a thin interface. The three-domain model (Figure 3 ) assumed that a well casing separates the two concentric annular columns for the flowing of water and steam, respectively. A test involving these two geometries was performed to verify if significant differences would occur. In other words, instead of designing a solid domain to represent the CSI/PAL/WS external column, a thin interface of the same column material was considered. The creation of a thin surface at the interface allows the modeling of the physics, such as the heat transfer through a material, without the need of creating a mesh for the external column. Furthermore, aiming at reducing computational effort, only a slice $\left(5^{\circ}\right.$ and $15^{\circ}$ ) of this computational domain was modelled.

Due to the complexity of the system and the disproportionality between width and height, the computational effort was very high. Therefore, in

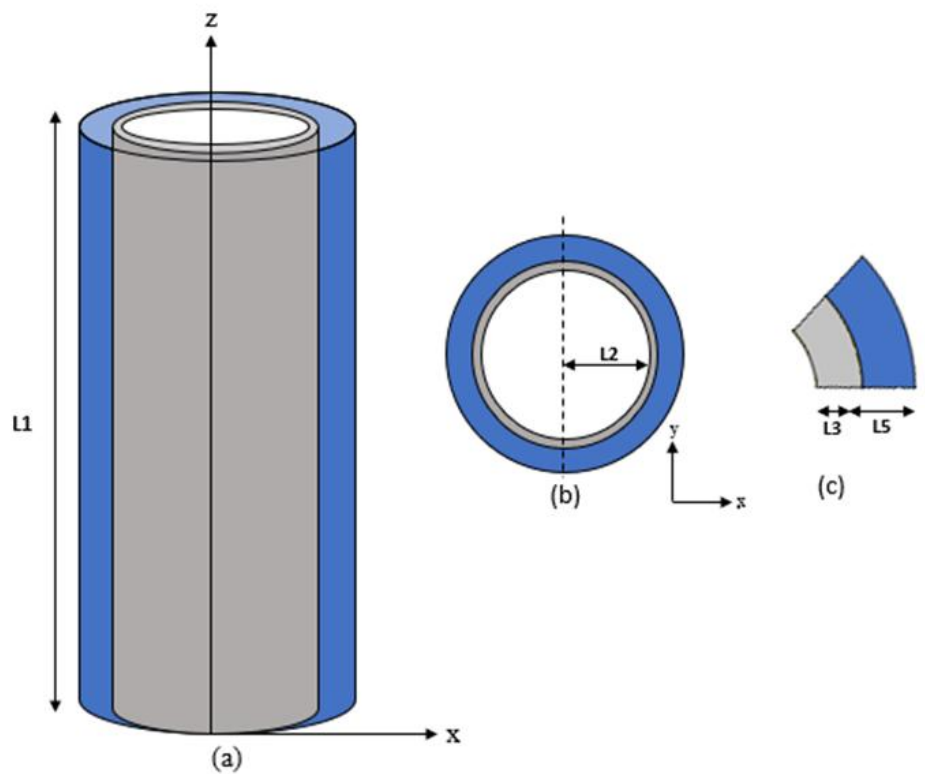

Figure 2. Geometry composed of two domains: (a) Complete geometry; (b) Upper view; (c) Slices of $5^{\circ}$ or $15^{\circ}$. Blue and gray colors represent the water and steam domains, respectively. 


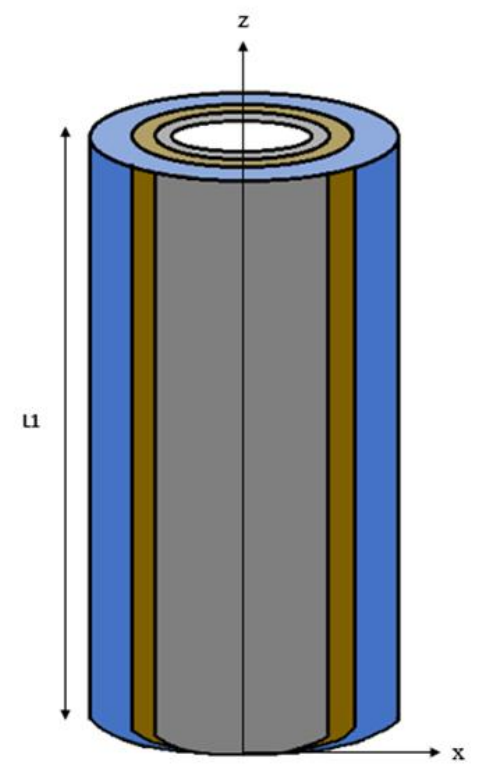

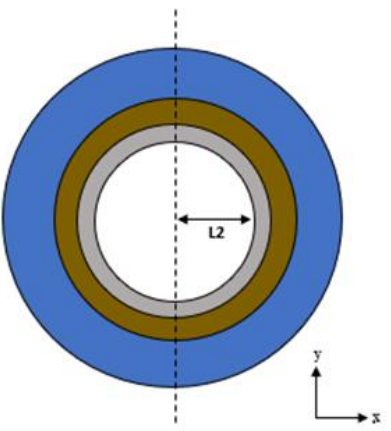

(b)

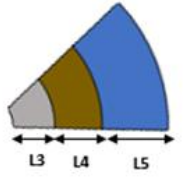

(c)

(a)

Figure 3. Geometry composed of three domains: (a) Complete geometry; (b) Upper view; (c) Slices of $5^{\circ}$ or $15^{\circ}$. Blue and gray colors represent the water and steam domains, respectively. The brown color was used to characterize the external column (solid domain).

order to make the simulation feasible, the system was divided into sections of 5-meter length each, being the output data of a simulation inserted as the boundary conditions of the following one. Finally, to test if this fractionation procedure would significantly influence the results, the simulation of two times of 5 meters of well was compared with the simulation of 10 meters at once. The dimensions of the geometry are shown in Table 1, and the references are shown in the geometry of Figure 2.

For mesh creation, the tool "Sizing Control" was used, where the edges of the geometry were selected separately and the refinement pattern was defined. For the z-axis edges, which represent a refinement in the radial direction, it was chosen the number of divisions and the growth rate relative to the edges to make the domain walls more refined. On the other hand, considering the $x$-axis edges (which represent a refinement in the axial direction) and the $y$-axis, only the number of divisions was chosen. To ensure the use of an appropriate mesh, which would not interfere with simulation results, besides representing consistent results, which would not require a large and unnecessary amount of computational effort, a mesh test was performed. This test included four hexahedral meshes, and started from a coarser mesh to a finer one to select the ideal size of the elements.

\subsection{Simulation data}

Water and steam were used as fluids. The water properties were provided by CFX database, whereas a real gas equation of state was necessary in the case of steam, due to the high-pressure value used in the simulation, which was too high to be considered as an ideal gas. The Peng-Robinson real gas model was chosen, for being one of the most widespread state equations employed in industry. The Peng-Robinson equation calculates pressure as a function of temperature and volume as shown in Eqs. 4 to 8.

$P=\frac{R T}{v-b}-\frac{\alpha(T)}{v^{2}+2 b v-b^{2}}$

Table 1. CSI/PAL/WS size used on the simulations.

\begin{tabular}{cc}
\hline Reference & Size $(\mathrm{mm})$ \\
\hline L1 & 5,000 \\
L2 & 44.450 \\
L3 & 5.765 \\
L4 & 6.885 \\
L5 & 22.555 \\
\hline
\end{tabular}


$b=0.0778 \times \frac{R T_{c}}{P_{c}}$

$\alpha(T)=\alpha_{0}\left[1+n\left(1-\sqrt{\frac{T}{T_{c}}}\right)\right]^{2}$

$\alpha_{0}=0.45724 \times \frac{R^{2} T_{c}^{2}}{P_{c}}$

$n=0.37464+1.54226 \omega-0.26993 \omega^{2}$

Where $P$ is the pressure, $T$ is the temperature, $v$ is the volume, $R$ is the constant of ideal gas, $T_{c}$ is the critical temperature, $P_{c}$ is the critical pressure, and $\omega$ is the acentric factor.

The CSI/PAL/WS system external column was built of steel with a thickness of $6.885 \mathrm{~mm}$, and the material properties were obtained from the CFX software database. Concerning geometry with two domains, the external column was considered as an interface between the water/steam domains. Water and steam domain walls were defined under the assumption of adiabatic and no slipping conditions. The hypothesis of adiabatic walls implies that the most critical temperature will be on the walls, thus, ensuring modeling the maximum possible temperature.

All simulations were performed considering a steady state and homogeneous model. The Shear Stress Transport (SST) turbulence model was chosen for simulation, because it is recommended for accurate boundary layer simulations. The model was designed to give highly accurate predictions of the onset, and the amount of flow separation under adverse pressure gradients by the inclusion of transport effects into the formulation of the eddy-viscosity. In the SST turbulence model, the turbulent eddy viscosity is computed from the turbulent kinetic energy $(k)$ and turbulent frequency $(\omega)$, as shown in Eq. (9).

$\mu_{T}=\rho k / \omega$

For initial, boundary, and output conditions of both water and steam domains, the parameters of pressure, temperature, and mass flow were supplied by the ENGEPET, and established as standard CSI/PAL/WS system operating conditions. These parameters are shown in Table 2.

\section{RESULTS AND DISCUSSION}

\subsection{Mesh test}

For performing the mesh test, a geometry with two domains and a slice of $5^{\circ}$ was used. The test was based on the size modification of the elements of each mesh. Furthermore, the refinement was performed according to $\mathrm{y}+$ requirements, which determine the optimal cell size near domain walls, and has values that can reach up to 5 for the SST model. Another important quality factor of the mesh that should be observed is the "aspect ratio," which is related to the degree that mesh elements are stretched; this value cannot exceed 100 . The number of elements of each mesh with their respective average $y+$ values and maximum aspect ratios are shown in Table 3 and Figure 4.

Table 2. Parameters used in the initial, boundary, and output conditions.

\begin{tabular}{ccc} 
& WATER & STEAM \\
\cline { 2 - 3 } Pressure & $1500 \mathrm{psi}$ & $1500 \mathrm{psi}$ \\
Mass flow & $0.01455 \mathrm{~kg} / \mathrm{s}$ & $0.01930 \mathrm{~kg} / \mathrm{s}$ \\
Temperature & $303.15 \mathrm{~K}$ & $588.15 \mathrm{~K}$ \\
\hline
\end{tabular}

Table 3. Statistics of developed meshes.

\begin{tabular}{cccc}
\hline Meshes & Number of elements & Average $\boldsymbol{y}+$ & Maximum aspect ratio \\
\hline 1 & 210,000 & 4.825 & 6.73 \\
2 & 300,000 & 3.994 & 11.67 \\
3 & 405,000 & 2.7615 & 25.79 \\
4 & 517,500 & 1.927 & 33.35 \\
\hline
\end{tabular}




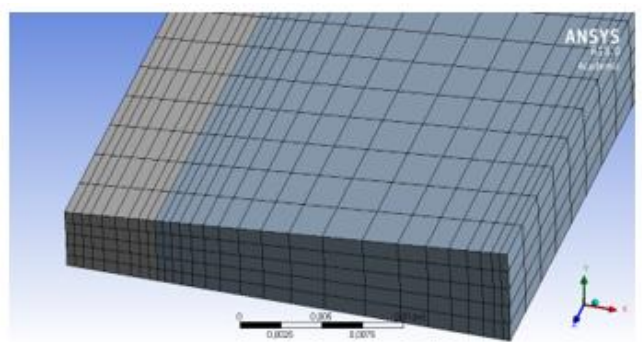

(a)

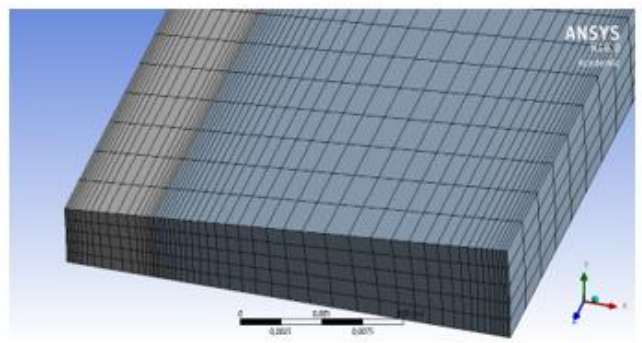

(c)

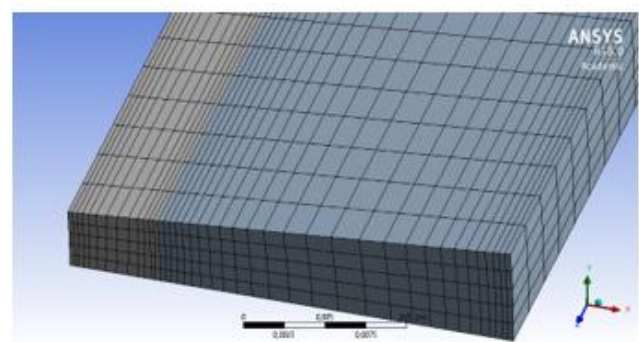

(b)

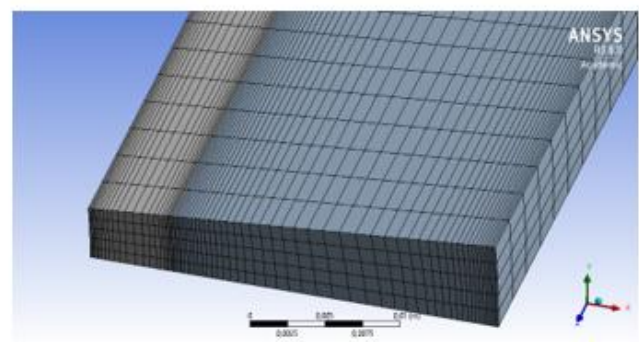

(d)

Figure 4. Refining comparison in geometric meshes. (a) Mesh 1 with 210,000 elements; (b) Mesh 2 with 300,000 elements; (c) Mesh 3 with 405,000 elements; (d) Mesh 4 with 517,500 elements.

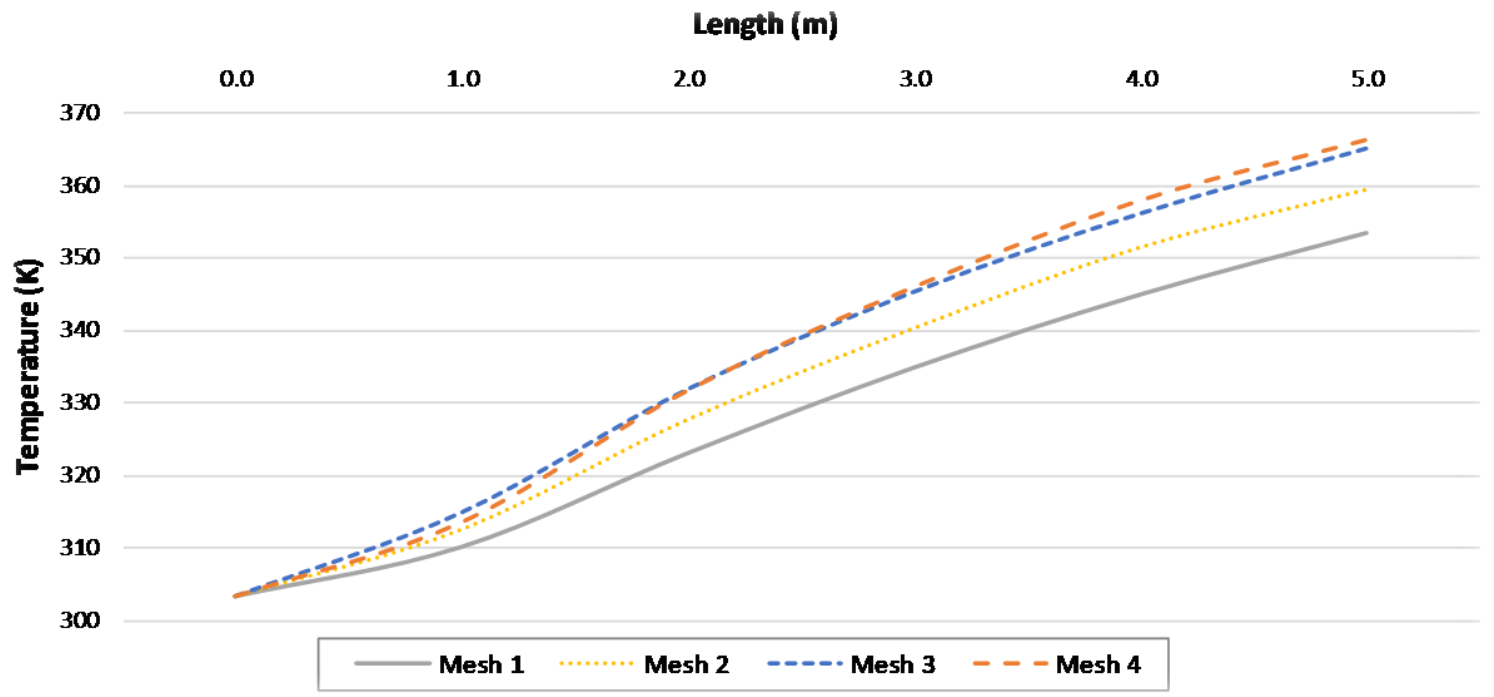

Figure 5. Comparison of the water temperature profile near the casing considering different meshes.

In order to select the best mesh size, the temperature profile in the casing wall was the parameter selected for observation, since it is the variable of interest in this work. Figure 5 shows a comparison graph where meshes 1 and 2 present differences in the temperature profiles, while meshes 3 and 4 demonstrate a quite similar behavior. Therefore, mesh 3 was selected due to the smaller number of elements and less computational effort.

\subsection{Symmetry test}

The symmetry test was used to check if simulations with column slices of $5^{\circ}$ would compromise the results, instead of using $15^{\circ}$ as it is used normally for symmetry tests (Silva et al., 2015). These tests employed the geometry with two domains. The $5^{\circ}$ mesh selected was mesh 3 $\left(405,000\right.$ elements), and the $15^{\circ}$ mesh $(630,000$ elements) followed the same refinement pattern of mesh 3. For comparison, temperature profiles were 


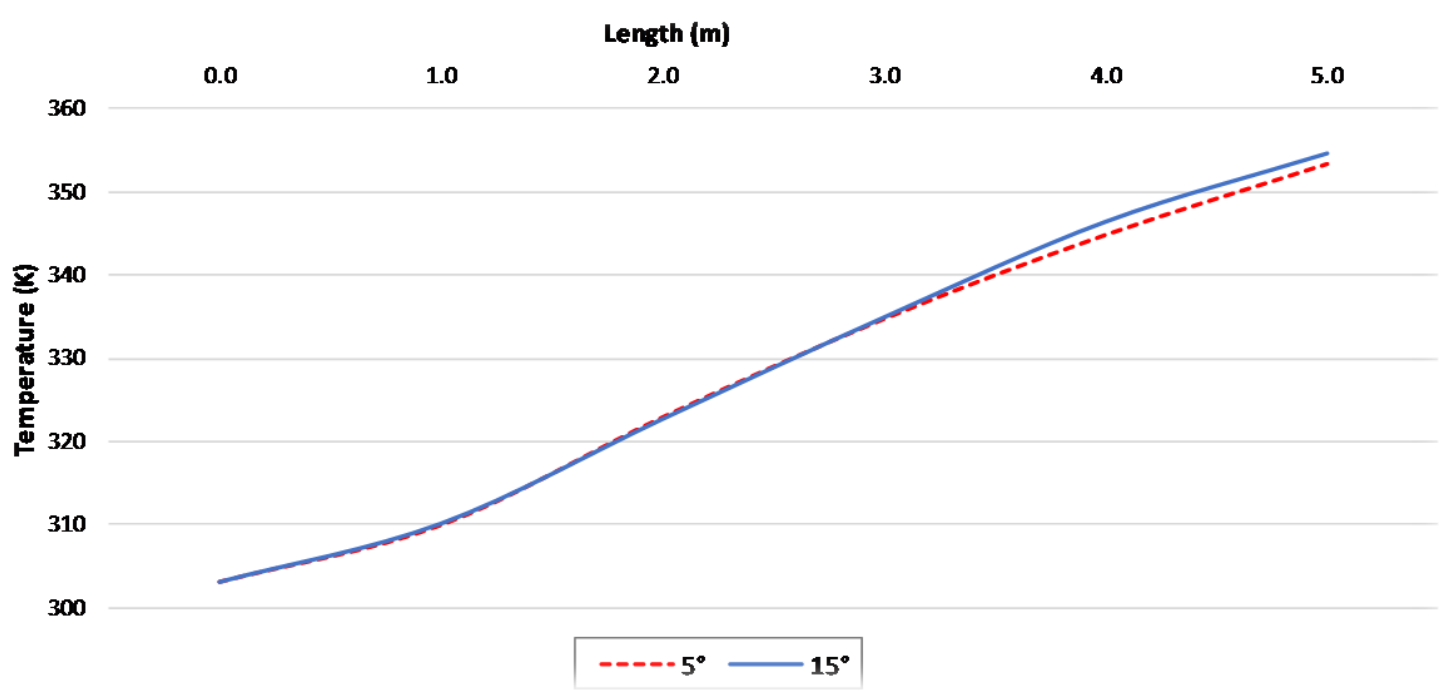

Figure 6. Comparison of water temperature profile near the casing between meshes with $5^{\circ}$ and $15^{\circ}$.

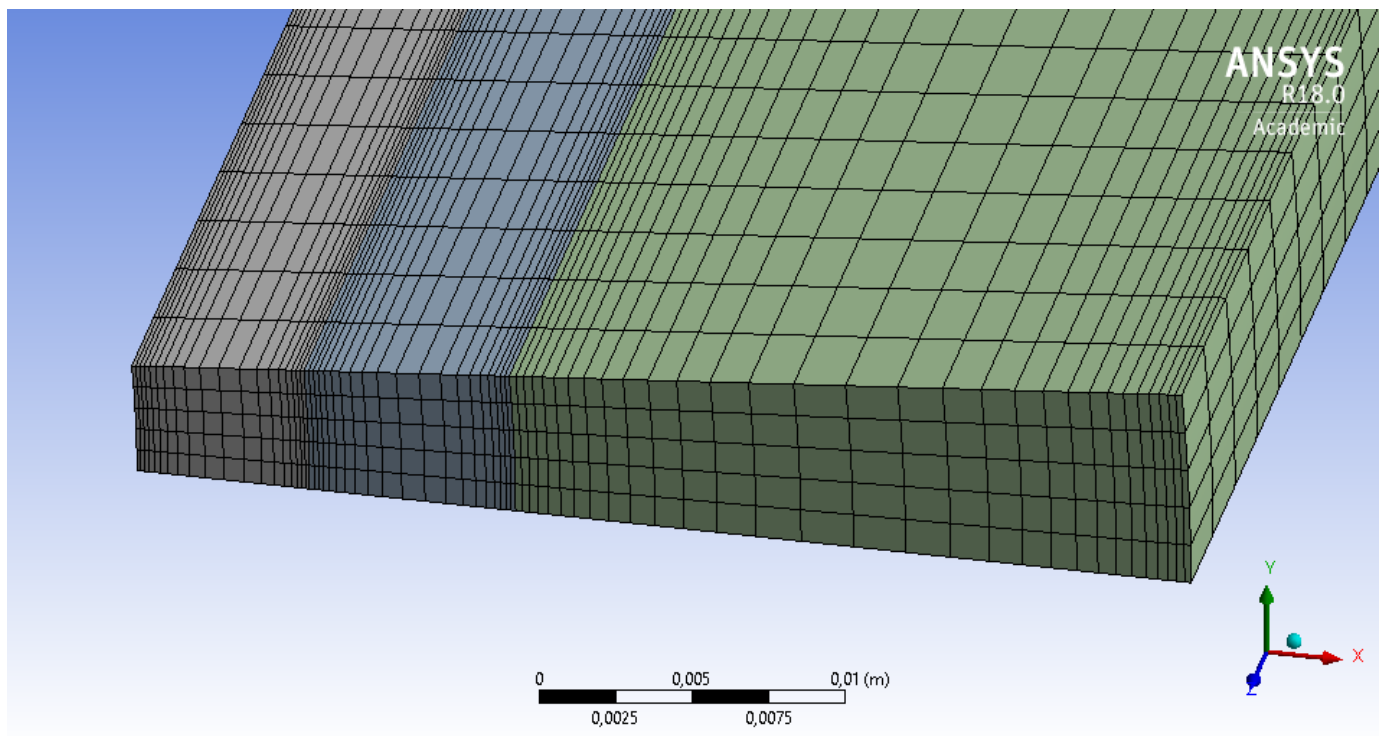

Figure 7. Geometry mesh with three domains.

analyzed in the same region. Figure 6 shows that there is no significant difference between the results obtained with meshes $5^{\circ}$ and $15^{\circ}$. Hence, the $5^{\circ}$ mesh was selected, due to its reduced number of elements and lower demand for computational efforts.

\subsection{Test with 2 and 3 domains}

The mesh generation with 3 domains followed the same refinement pattern described earlier for the two-domain case. The mesh of the solid domain was generated considering the same number of divisions and growth rate as the steam domain elements due to their similar thicknesses, as shown in Figure 7. In Figure 8 one can see that there was a small discrepancy between the two different profiles in the first 2 meters of well length. After that, however, differences vanished and the three-domain model did not prove to present advantages. Therefore, the mesh with two domains was selected due to its simplicity and lower computational effort.

\subsection{Fractionation test of the well}

Mesh 1 (210.000 elements) was used for the fractioning test, as described in the methodology, 


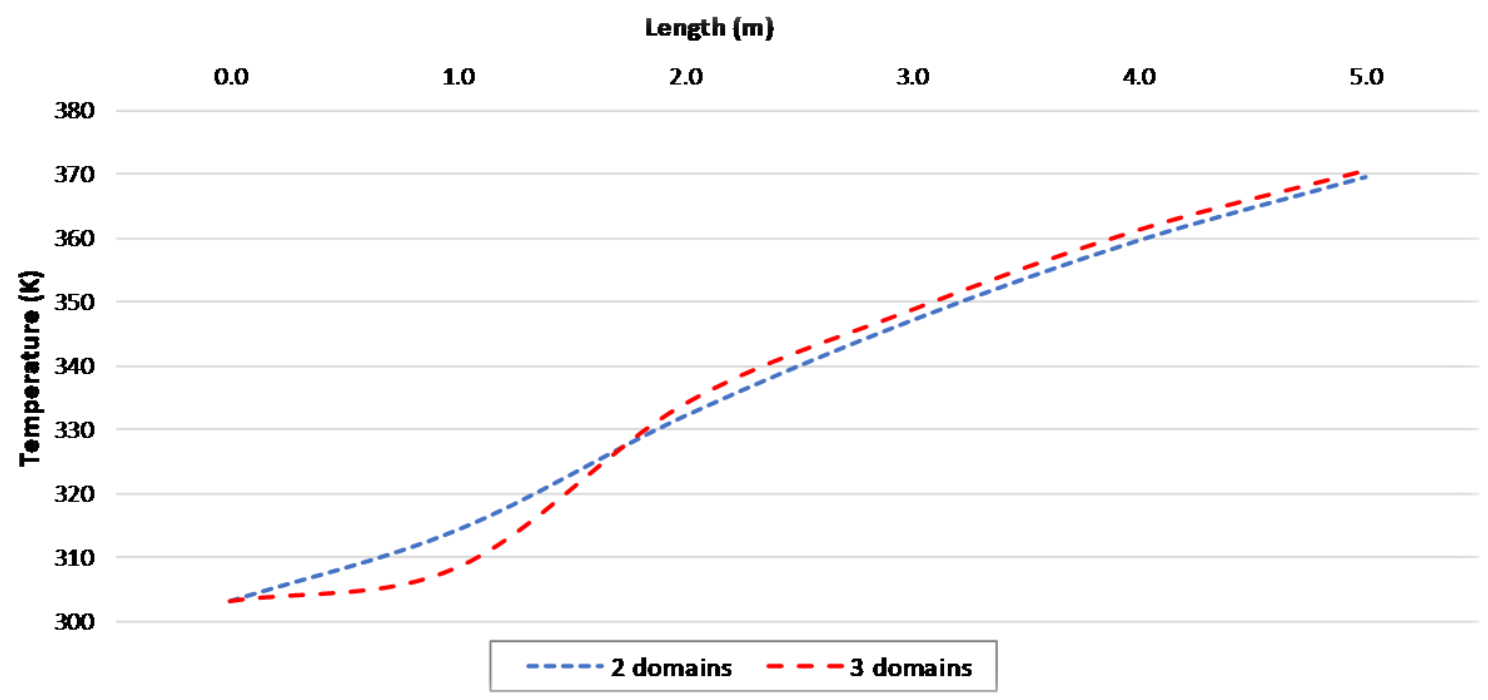

Figure 8. Comparison of water temperature profile near the casing of the meshes with two and three domains.

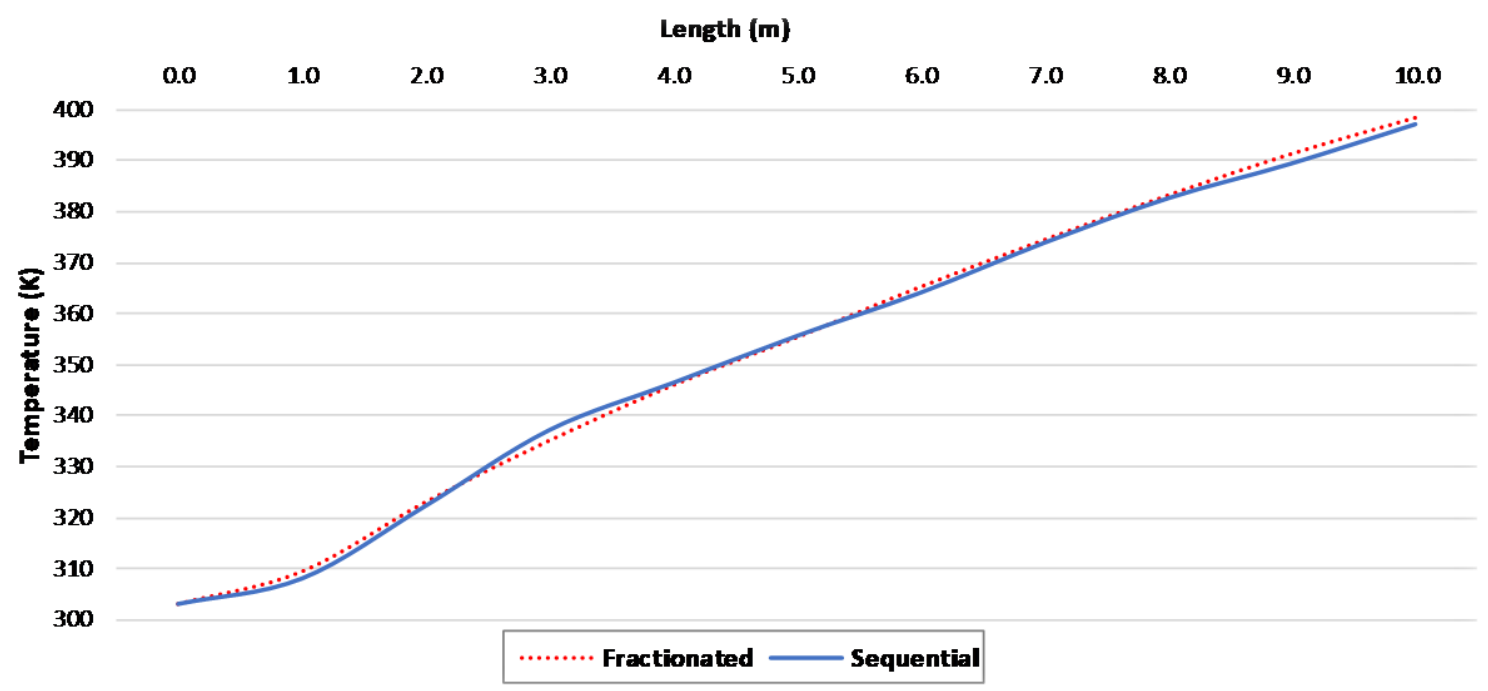

Figure 9. Comparison of water temperature profiles near the casing corresponding to the fractionated simulation (each $5 \mathrm{~m}$ ) and sequential simulation (simulation of $10 \mathrm{~m}$ ).

because it was the one with the lowest number of elements and also for generating faster simulation responses. The ten-meter length simulation is referred to as "sequential," while the other simulation composed by two fractions of five meters is called "fractionated". Figure 9 shows no significant difference between the two curves, indicating that it is possible to reach reliable data when performing fractionated simulations. This result is extremely positive as it allows deep wells studies by CFD simulation.

\section{CONCLUSION}

Cyclical Steam Injection and Pneumatic Artificial Lift (CSI/PAL), and Cyclical Steam Injection and Pneumatic Artificial Lift with Water Seal CSI/PAL/WS technologies are very promising as EOR techniques for enhancing the productivity of mature and high viscosity oil fields. Because these techniques are still little known, there is a need for more investigations regarding their technical and economic viabilities. 
This work proposes a three dimensional CFD model for simulating the thermal exchange profile of a CSI/PAL/WS system. In general, preliminary results indicate a great potential to be used in the design of new systems through the assessment of operating conditions.

The model with a mesh of 405000 elements, a geometry with only two domains (water and steam), disregarding the metal casing, and an angular slice of $5^{\circ}$ proved to be adequate to the simulation of the thermal profile of the CSI/PAL with water seal. Furthermore, the proposal of fractionating the length of the well and performing subsequent simulations of the fractions can circumvent the difficulty in simulating large lengths of wells, and may contribute significantly to the expansion of the study in this area.

The proposed model makes it possible to carry out simulation tests for different water and steam flow rates, as well as establishing a correlation between them. Moreover, it can be used to simulate operations involving CSI/PAL with water seal (CSI/PAL/WS) and predict situations where casing temperature may well operating limits.

\section{ACKNOWLEDGMENTS}

The authors of the present work would like to acknowledge ENGEPET for offering technical support and for providing the data used in the CSI/PAL system. They would also like to recognize the financial support provided by CAPES, and all pedagogical and technical assistance supplied by the Graduate Program in Chemical Engineering from the Federal University of Bahia and the Graduate Program in Chemical and Biochemical Processes Engineering from the Federal University of Rio de Janeiro.

\section{REFERENCES}

Abedini, A.; Torabi, F. Parametric study of the cyclic $\mathrm{CO}_{2}$ injection process in light oil systems. Industrial and Engineering Chemistry Research, v. 52, p. 15211-15223, 2013.

https://doi.org/10.1021/ie402363h
Al Hinai, N. M.; Saeedi, A.; Wood, C. D.; Valdez, R.; Esteban, L. Experimental Study of miscible thickened natural gas injection for enhanced oil recovery. Energy and Fuel, v. 31, p. 4951-4965, 2017. https://doi.org/10.1021/acs.energyfuels.7b00314

Alvarez, J.; Han, S. Current overview of cyclic steam injection process. Journal of Petroleum Science and Research, v.2, p. 116-127, 2013.

Belsky, A. A.; Korolyov, A. Thermal oil recovery method using self-contained windelectric sets. Journal of Physics: Conference Series, v. 1015, 052001, 2018. https://doi.org/10.1088/1742$\underline{6596 / 1015 / 5 / 052001}$

Bo, K. Simulation of casing stress in thermal recovery production wells Advances in Petroleum Exploration and Development, v. 7(1), p. 38-41, 2014.

Costa, S. E. D.; Barros Neto, E. L.; Oliveira, M. C. A.; Santos, J. S. C. Mechanical and petrophysical analysis of synthetic sandstone for enhanced oil recovery applications. Brazilian Journal of Petroleum and Gas, v.11, n.3, p.131-140, 2017. https://doi.org/10.5419/bjpg2017-0011

Franco, Z. A.; Miyaji, M. Processo e sistema de injeção de vapor para recuperação de petróleo com elevação simultânea do petróleo produzido pelo poço. Patente PI 0306290-2 (22). Application in $07 / 10 / 2003$, 2003. (in Portuguese)

Gomez, D.A.; Medronho, R.A.; Nele, M.; Pinto, J.C.C.S. Estudo do escoamento compressível de gás natural em regiões anulares com restrições em sistemas BPZ para a elevação de petróleo. In: Anais do XIX Congresso Brasileiro de Engenharia Química, 2012, Búzios-RJ, p. 9822-9831, 2012. (in Portuguese).

Oliveira, L. M. T. M.; Marinho, J. L. G.; Pimentel, W. R. O. Simulação Numérica da Recuperação Térmica de Petróleo Utilizando Injeção de Água Quente. In: Anais do I Congresso Nacional de Engenharia de Petróleo, Gás Natural e Biocombustíveis, Campina Grande, 2015, v.1. (in Portuguese).

Pei, H.; Zhang. G.; Ge, J.; Zhang, L.; Wang, H. Effect of polymer on the interaction of alkali with heavy oil and its use improving oil recovery. Colloids and Surfaces A: Physicochemical and Engineering Aspects, v. 446, p. 57-64, 2014. https://doi.org/10.1016/j.colsurfa.2014.01.031 
Rellegadla, S.; Prajapat, G.; Agrawal, A. Polymers for enhanced oil recovery: fundamentals and selection criteria. Appl Microbiology Biotechnology, v. 101, p. 4387-4402, 2017. https://doi.org/10.1007/s00253-017-8307-4

Rego, F. B.; Botechia, V. E.; Schiozer, D. J. Heavy oil recovery by polymer flooding and hot water injection using numerical simulation. Journal of Petroleum Science and Engineering, v. 153, p. 187196, 2017.

https://doi.org/10.1016/i.petrol.2017.03.033

Safi, R.; Agarwal, R. K.; Benerjee, S. Numerical simulation and optimization of $\mathrm{CO}_{2}$ utilization for enhanced oil recovery from depleted reservoirs. Chemical Engineering Science, v. 144, p. 30-38, 2016. https://doi.org/10.1016/i.ces.2016.01.021

Silva, J. O. C.; Fernandes, T. S.; Júnior, P. F. M.; Ledo, L. F. R.; Hanriot, S. M.; Maia, C. B. Influência do regime de escoamento em uma chaminé solar de pequeno porte. In.: Congresso de Métodos Numéricos em Engenharia, Lisboa, Portugal, 2015. (In Portuguese).

Sousa, M. F. C.; Cruz, W. R. S.; Medronho, R. A.; Silva, G. F. Estudo comparativo entre os métodos contínuo e BPZ de elevação artificial de petróleo. In: Anais do XX Congresso Brasileiro de Engenharia Química, 2014, Florianópolis, Blucher Chemical Engineering Proceedings, v.1, n.2, p. 6466-6473. São Paulo: Blucher, 2015. (in Portuguese)
Wang, Y.; Zhang, L.; Deng, J.; Wang, Y.; Ren, S.; $\mathrm{Hu}, \mathrm{C}$. An Innovative air assisted cyclic steam stimulation technique for enhanced heavy oil recovery. Journal of Petroleum Science and Engineering, v. 151, p. 254-263, 2017. https://doi.org/10.1016/i.petrol.2017.01.020

Yin, Y.; Liu, Y. FEM Analysis of fluid-structure interaction in thermal heavy oil recovery operations. Sustainability, v. 7, p. 4035-4048, 2015. https://doi.org/10.3390/su7044035

Zhang, K.; Feng, Y.; Schwarz, P.; Wang, Z.; Cooksey, M. Computational fluid dynamics (CFD) modeling of bubble dynamics in the aluminum smelting process. Industrial and Engineering Chemistry Research, v. 52, p. 11378-11390, 2013. https://doi.org/10.1021/ie303464a 